\title{
Confiança nas polícias: percepç̃ão dos residentes e desafios para a gestão
}

\author{
Marcos Flávio Rolim* \\ Daiana Hermann**
}

\section{Resumo}

A partir das evidências disponíveis que sustentam a importância da confiança da população nas polícias, salientando o quanto o fenômeno é decisivo para a eficiência do trabalho de policiamento e para a própria adesão da cidadania aos ditames legais, o texto analisa os resultados colhidos em pesquisa de vitimização realizada em Porto Alegre, em 2017, na parte que tratou da percepção dos residentes sobre o trabalho da Polícia Militar e da Polícia Civil. A análise dos dados evidencia baixas taxas de confiança para ambas as polícias estaduais - Indicador de Confiança Policial de 49,2\% para a Brigada Militar e de 53,7\% para a Polícia Civil. A menor confiança nas polícias concentra-se entre as populações mais jovens e mais pobres. No caso da Polícia Militar, encontrou-se diferença estatisticamente significativa também para menor confiança entre a população negra, o que sugere padrões de atuação distintos em uma mesma cidade, a depender dos grupos sociais abordados ou atendidos pelas corporações. Ao final, apresentamos diretrizes que podem auxiliar no processo de definição de políticas específicas capazes de aumentar a confiança do público nas instituições policiais.

Palavras-chave: Confiança na polícia, Justiça procedimental, Legitimidade e eficiência policial.

*Tribunal de Contas do Estado do Rio Grande do Sul. Porto Alegre, RS, Brasil

**Universidade Federal do Rio Grande do Sul. Porto Alegre, RS, Brasil 
Trust in police forces: perception of residents and challenges for public administration

\section{Abstract}

Based on available evidence that points to the importance of the population's trust in police forces, emphasizing the decisive role of such trust for the efficiency of policing work and for the very adherence of citizens to the law, the paper analyzes the results of a victimization survey conducted in Porto Alegre in 2017, drawing particularly on results regarding the residents' perception of the work of the Military Police and the Civil Police. Data analysis shows low trust rates for both state polices, with the Police Trust Indicator reaching 49,2\% for the Military Police and 53,7\% for the Civil Police. The lowest rates of trust in the police are concentrated among younger and poorer populations. In the case of the Military Police, a statistically significant difference was also found for lower trust among the Afro-descendant population, which suggests different patterns of performance in the same city, depending on the social groups addressed or served by the corporations. Finally, we propose some guidelines that can help in the process of defining specific policies capable of increasing public confidence in police institutions.

Keywords: Trust in police forces, Procedural justice, Police legitimacy and efficiency.

\section{Confiança e legitimidade policial}

tema da confiança da população nas polícias deve merecer
consideração especial dos pesquisadores e dos gestores em Segurança
Pública no Brasil, a começar pelos próprios dirigentes das polícias. A primeira e mais importante razão para tanto é a consciência de que baixos níveis de confiança nas polícias estão correlacionados a altas taxas de subnotificação criminal (dark rate) (Hagan; Albonetti, 1982; Sherman, 1993), mas, sobretudo, a um fluxo reduzido de informação dos residentes aos policiais.

Informação, como se sabe, é o mais importante recurso que um agente encarregado de fazer cumprir a lei precisa ter. Quando os policiais não possuem informações, habitam o desconhecido, têm menos chance 
de produzir bons resultados e estão mais expostos a riscos. As polícias mais eficientes do mundo exigem muito na seleção e na formação de seus membros, para que suas relações com a cidadania sejam respeitosas, equitativas e atenciosas. Este é também um tema central para a carreira dos policiais e para as avaliações de desempenho das próprias instituições.

Quando as pessoas confiam nas polícias, as instituições são admiradas e respeitadas, o que é sempre preferível à situação em que as polícias são temidas. As evidências mostram que uma maior confiança pública nas polícias está correlacionada à disposição de se submeter mais amplamente às orientações policiais e a um respeito maior à lei (Bradford, 2009; Tyler, 1990; Tyler; Huo, 2002; Tyler; Fagan, 2008). Ao contrário, quando as polícias perdem legitimidade aos olhos do público, as pessoas resistem mais às solicitações dos agentes; manifestam maior probabilidade de prestar queixas contra os policiais e ficam menos dispostas a cooperar e a relatar o que sabem em uma investigação (Hawdon 2008; Kane 2005; Mastrofski et al., 1996).

A capacidade de resolver problemas considerados importantes pelas comunidades e a percepção de que os policiais agem de maneira justa constituem a base da legitimidade do policiamento. A preocupação com a justiça da ação policial tem sido objeto de crescente atenção, em muitos países, em pesquisas e orientações sobre Justiça Procedimental (Procedural Justice $)^{1}$. Se as pessoas percebem que os policiais se conduzem de forma correta, então as possibilidades de colaboração da cidadania com a polícia serão expressivas (Bradford et al., 2009; Tyler; Fagan, 2008). Polícias com escassa legitimidade têm muito mais dificuldade, são mais custosas e menos eficientes. Zanetic et al (2016) destacam que o agravamento dessa situação pode fazer com que a polícia pare de ser chamada em várias situações e que a opção pela resolução privada de conflitos, com atos ilegais e violentos, se torne comum, agravando o quadro geral da insegurança.

1 Uma revisão sobre o tema no que se refere à atividade policial pode ser encontrada em Kunard e Moe (2015). 


\section{Medindo a confiança nas polícias}

A melhor forma de se medir a confiança do público nas polícias é por intermédio de estudos do tipo survey. Tradicionalmente, pesquisa de vitimização no Reino Unido e nos Estados Unidos contaram sempre com perguntas sobre esse tema. Até 2009, a pergunta básica sobre o ponto no British Crime Survey ${ }^{2}$ era "Como você avalia o trabalho que a polícia está fazendo nesta região?" (Stanko; Bradford, 2009). Quando medimos taxas de confiança apenas a partir de uma impressão genérica, entretanto, não identificamos os motivos pelos quais as pessoas expressam suas opiniões. A avaliação dos residentes pode ser influenciada, no mais, por várias razões, desde o atendimento que receberam, a visibilidade dos policiais e o grau de interação da polícia com seu bairro, até a notícia que tiveram sobre o esclarecimento de um crime ou sobre corrupção ou violência policial. A coesão social e a confiança maior ou menor no próprio Poder Público também podem influir nesse tipo de avaliação. Jang et al. (2010) encontraram que países com altas taxas de homicídio possuem baixas taxas de confiança nas polícias e que quanto maior a solidez do regime democrático, maior a confiança nas polícias ${ }^{3}$. Já para Stanko e Bradford (2009), há quatro elementos centrais que afetam a confiança nas polícias: a) a percepção sobre a efetividade do trabalho policial, b) a percepção sobre a justiça (fairness) do tratamento, quando das interações com os policiais, c) o nível de engajamento das polícias com as comunidades e d) as preocupações do público com a desordem local.

Tendo presente a necessidade de informações mais específicas a respeito da percepção do público sobre o trabalho policial, o Serviço da Polícia Metropolitana de Londres (Metropolitan Police Service) tem aplicado surveys abarcando inúmeros aspectos da atividade policial e de seus resultados. Sobre a efetividade da polícia, os pontos são: a) prevenção ao terrorismo;

${ }^{2} \mathrm{O}$ serviço é atualmente denominado Crime Survey for England \& Wales.

${ }^{3}$ Onde há ditaduras é comum que a confiança nas polícias seja baixa, porque elas costumam ser empregadas na perseguição aos adversários do regime (Cao; Zhao, 2005, apud Jang et al., 2010). 
b) imediata resposta às emergências $\mathrm{c}$ ) visibilidade do patrulhamento; $d$ ) atitude diante do crime de arma de fogo; e) apoio às vítimas e testemunhas; f) principais eventos da polícia; g) atitude diante do tráfico e do uso de drogas; e h) atitude frente à direção perigosa. Sobre o tratamento justo, as questões envolvem concordância ou discordância com quatro afirmações: a) os policiais irão tratá-lo com respeito se você se encontrar com eles; b) os policiais tratam todas as pessoas dessa área de forma justa, independente de quem sejam as pessoas; c) os policiais são prestativos e d) os policiais são amigáveis e acessíveis. Quanto ao engajamento comunitário, as questões também envolvem concordância/discordância com as seguintes afirmações: a) você pode confiar que os policiais desta área estarão lá quando você precisar deles; b) os policiais compreendem os problemas que afetam a comunidade nesta área; c) os policiais estão lidando com os temas que importam para esta comunidade e d) os policiais desta área escutam os residentes. Esse esforço foi tomado como referência para nosso estudo em Porto Alegre quanto ao tema da confiança nas polícias estaduais, como se verá.

Os indicadores disponíveis permitem concluir que as taxas de confiança da população brasileira nas polícias são baixas, como regra. Se tomarmos as evidências colhidas pelo World Values Survey $(2011)^{4}$, veremos que o Brasil ocupa a 34aㅡ posição entre 47 países analisados quanto ao nível de confiança da cidadania em suas polícias. Nas democracias mais consolidadas, é comum encontrarem-se taxas de confiança nas polícias superiores a 90\%, enquanto, no Brasil, a taxa média é de 44,9\%, percentual abaixo da média dos países pesquisados pelo estudo, que foi de 58,4\% (Silva; Braga, 2012, apud Silva; Beato, 2013).

A par desse problema, não se firmou no Brasil uma tradição de acompanhamento e medição da confiança da população nas polícias e os estudos específicos são em pequeno número. Silva e Beato (2013), por exemplo, encontraram uma taxa média de confiança nas polícias, em uma escala de 0 a 10, de 5,8. Pesquisa do IPEA (2011) encontrou que

${ }^{4}$ WVS (2011) - estudo com dados de 2005 a 2008, disponível em: <http://www. worldvaluessurvey.org $>$. 
apenas $25 \%$ da população brasileira confia na polícia enquanto $75 \%$ não confiam. Santos (2002), por seu turno, encontrou que 34,1\% dos residentes na região metropolitana de Belo Horizonte possuem medo da polícia; 18,3\% acreditam que há "um número grande de policiais corruptos", 33,1\% que há "um número razoável" e 28,8\% acreditam que há um "pequeno número de policiais corruptos". Ainda, 52,4\% da amostra entende que "a polícia trata os ricos melhor que os pobres". As diferenças nos índices dos estudos estão vinculadas a naturezas distintas de investigação, uma vez que não contamos com um padrão para perguntas e também não lidamos com uma mesma metodologia, o que dificulta a comparação dos dados. Algumas pesquisas de vitimização realizadas no Brasil aplicaram questões a respeito do tema, colhendo também a percepção dos residentes a respeito da preparação dos policiais e sobre sua eficiência. Esse é o caso, por exemplo, das pesquisas realizadas por CRISP/UFMG em Belo Horizonte, em 2002; Curitiba e Foz do Iguaçu, em 2005; Região Metropolitana de Belo Horizonte, em 2005; e da pesquisa do NUPEVI/IMS/UERJ/CRISP/UFMG na Cidade do Rio de Janeiro, em 2006 (Beato, 2009) ${ }^{5}$. Entre os estudos específicos sobre confiança na polícia, Silva e Beato (2013), examinando os dados da pesquisa de vitimização da Região Metropolitana de Belo Horizonte, que envolveu 29 Municípios em MG, concluíram que é comum que as pessoas confundam as prerrogativas das polícias com aquelas típicas do sistema de Justiça Criminal e que o contato com os policiais - especialmente quando há abordagens feitas pela polícia - diminuem a confiança dos residentes. Nas cidades menores, a confiança na polícia é maior. Quanto aos fatores que melhoram as taxas de confiança, os autores encontraram que a percepção a respeito da eficiência da polícia em solucionar problemas relacionados à violência é o mais operante deles.

\footnotetext{
${ }^{5}$ Tais estudos encontraram indicadores de baixa confiança dos residentes na Polícia Militar, com uma variação de 30,1\% de baixa confiança em Foz do Iguaçu a 60,9\% de baixa confiança no Rio de Janeiro. No caso de Belo Horizonte, o indicador de baixa confiança foi de 47,5\% em 2002 e de 38,8\% em 2005. Em Curitiba, 40,5\% dos residentes tinham baixa confiança na PM. A percepção da população a respeito da eficiência dos PMs e sobre o seu preparo foram igualmente negativas.
} 


\section{O estudo de Porto Alegre}

Com relação às percepções da população sobre as polícias em Porto Alegre, estudo de Shirley $(1997)^{6}$ havia já identificado o medo que os moradores da periferia sentiam das polícias, assim como a impressão generalizada entre os mais pobres a respeito da corrupção policial, destacando esses temas como desafios centrais. A confiança dos residentes nas polícias civil e militar no RS, entretanto, é tema pouco estudado. Recentemente, integramos os esforços de pesquisa de vitimização na cidade de Porto Alegre $^{7}$, onde se recolheu a percepção dos residentes sobre vários temas, entre eles sua avaliação sobre o trabalho da Brigada Militar (BM) e da Polícia Civil (PC). A amostra, quantitativa probabilística aleatória, foi realizada com 1.000 entrevistas domiciliares nos setores censitários da cidade, em suas oito regiões, com residentes maiores de 16 anos, estratificados por sexo, faixas etárias e níveis de renda, reunindo outras variáveis como escolarização, composição étnica ${ }^{8}$, orientação sexual e pertencimento a religiões, com margem de erro de $3 \%$ e grau de confiança de $95 \%$.

${ }^{6} \mathrm{O}$ trabalho foi realizado entre 1985 e 1988, com a participação de Claudia Fonseca, Cesar Augusto Avancinni, Sergio Martins de Barros e Jurema Brittes, na Vila Vargas, Morro da Cruz.

${ }_{7}$ Pesquisa do Instituto Cidade Segura, patrocinada pelo Sindicato dos Policiais Federais do Rio Grande do Sul (SINPEF/RS), pelo Sindicato dos Escrivães, Inspetores e Investigadores de Polícia (UGEIRM) e pelo Sindicato dos Policiais Rodoviários Federais do Rio Grande do Sul (SINPREF-RS), realizada pelo Instituto de Opinião Pública, com campo em outubro de 2017. Relatório disponível em: <https://goo.gl/P7BC9U>.

${ }^{8} \mathrm{~A}$ cor ou raça autodeclarada dos entrevistados foi coletada com base nas cinco categorias adotadas pelo IBGE (preta, parda, branca, amarela e indígena). Para fins de análise, as categorias "parda" e "preta" foram agrupadas sob a categoria "negros". A amostra da pesquisa, embora não estratificada por raça/cor, guarda semelhança proporcional com a composição étnico-racial da população de Porto Alegre segundo Censo Populacional do IBGE de 2010 (brancos: 79,2\%; negros: 20,2\%; amarelos: 0,3\% e indígenas: 0,2\%). A proporção verificada na pesquisa foi de $71,5 \%$ de brancos, $27,2 \%$ de negros, $0,3 \%$ de amarelos e $0,9 \%$ de indígenas. Nas comparações dos resultados em função do pertencimento étnicoracial dos entrevistados os dados foram agrupados nas categorias "brancos" e "negros". Não foram realizadas conclusões acerca dos autodeclarados "amarelos" e "indígenas" pois estes representam, na amostra de 1.000 casos, um número absoluto muito pequeno, o que gera distorções nos resultados. 
Seguindo a sugestão de Rosenbaum et al (2015), lidamos, separadamente, com a percepção dos residentes que tiveram contato com a Polícia, desde os que foram abordados por policiais até os que reportaram crimes às polícias e/ou que lhes demandaram providências. Para comparar de forma equilibrada as avaliações, excluímos do cálculo do índice de confiança os resultados das perguntas sobre a experiência dos residentes que foram apenas abordados pela Brigada Militar (porque, como regra, as pessoas não são abordadas pela Polícia Civil).

O trabalho, assim, construiu o Indicador de Confiança Policial (ICPol) para cada instituição a partir da opinião daqueles que procuraram as polícias com 11 variáveis independentes: a) equidade no tratamento recebido; b) satisfação com o atendimento; c) satisfação com as informações recebidas; d) percepção sobre resolução de problemas dos residentes; e) expectativa da disponibilidade policial; f) qualidade da interação com os residentes; g) qualidade das decisões gerais tomadas pelas polícias; h) preparação dos policiais; i) violência policial; j) honestidade policial; k) resultados obtidos contra o crime. Na elaboração das perguntas (em anexo), foram adaptadas algumas das formulações utilizadas pelo Metropolitan Police Service.

\section{a. Equidade no tratamento recebido pela Polícia}

Dentre os entrevistados que procuraram a Brigada Militar, 63,1\% avaliam que foram tratados de forma equânime. As avaliações negativas concentram-se entre os mais jovens ${ }^{9}$, entre os mais pobres e entre os menos escolarizados ${ }^{\mathbf{1 0}}$. Já dentre os entrevistados atendidos pela Polícia Civil, 82,5\% entendem que foram tratados com equidade, sem diferenças estatisticamente significativas quanto ao perfil dos entrevistados.

\section{b. Satisfação com o atendimento}

Pouco mais de 1/3 dos entrevistados manifestaram satisfação com o atendimento que receberam da Brigada Militar ou da Polícia Civil, quando

\footnotetext{
${ }^{9}$ Teste realizado: Regressão Logística: Sig $=0,018$.

${ }^{10}$ Teste realizado: Regressão Logística: Sig $=0,001$.
} 
pediram ajuda ou acionaram o 190; 34,6\% disseram estar satisfeitos com o atendimento da BM, e 38,4\% com o atendimento da PC.

\section{c. Satisfação com as informações recebidas}

Cerca de 2/3 dos entrevistados (66,4\%) que procuraram a Brigada Militar nos últimos 12 meses consideram que os policiais responderam de forma satisfatória suas perguntas. Dentre os que procuraram a Policia Civil no período, o percentual de satisfação foi mais elevado: 74,6\%.

\section{d. Percepção sobre resolução de problemas dos residentes}

A Brigada Militar recebeu uma avaliação mais positiva - em comparação com a Polícia Civil - no que tange ao juízo de que realizam um bom trabalho junto aos moradores para resolver os problemas da comunidade: 43,7\% acreditam que a Brigada colabora na resolução dos problemas dos residentes, contra 38,4\% que têm a mesma impressão sobre a Civil.

\section{e. Expectativa de disponibilidade dos policiais}

Entre os entrevistados, 37,8\% acreditam que os policiais militares estarão disponíveis quando eles realmente precisarem deles. A expectativa de disponibilidade é um pouco superior quanto aos policiais civis, com $41,9 \%$ de respostas positivas.

\section{f. Qualidade da interação com os residentes}

Entre os entrevistados, 41,5\% entendem que a Brigada Militar escuta os moradores do bairro e compreende os problemas que afetam a comunidade. Este percentual é um pouco superior ao dos entrevistados que têm a mesma impressão quanto à Polícia Civil (38,1\%).

\section{g. Qualidade das decisões gerais tomadas pelas polícias}

Pouco mais de 4 em cada 10 entrevistados confiam que a Brigada Militar e a Polícia Civil estão tomando decisões que são boas para todos na cidade. 


\section{h. Preparação dos Policiais}

Entre os entrevistados, 45,2\% acreditam que os policiais militares são bem preparados para o trabalho que realizam. Neste item, os policiais civis obtiveram resultado sensivelmente mais positivo: $55,2 \%$ da amostra os consideram bem preparados.

\section{i. Violência Policial}

Entre os entrevistados, 58,7\% entendem que os policiais militares não são violentos e que agem de forma respeitosa com as pessoas. Já entre os entrevistados mais jovens - sobretudo entre aqueles de até 24 anos, mas também entre adultos entre 25 e 39 anos (Teste realizado: Regressão Logística. Sig =0,000) - há mais avaliações negativas da Brigada Militar no que tange à violência policial. Da mesma forma, pessoas autodeclaradas negras (pretas/pardas) (Teste realizado: Regressão Logística. Sig = 0,031), com menor escolaridade (Teste realizado: Regressão Logística: Sig = 0,041) e com renda mais baixa (Teste realizado: Regressão Logística: Sig $=0,006)$ tendem a avaliar a BM como sendo violenta e desrespeitosa. No que tange à Policia Civil, $72,4 \%$ acreditam que os policiais não são violentos e que costumam agir de forma respeitosa com as pessoas. Não houve diferenças estatisticamente significativas quanto aos perfis dos residentes na avaliação da $\mathrm{PC}$.

\section{j. Honestidade dos policiais}

Pouco mais de $60 \%$ dos entrevistados acreditam que são muito raros os casos de policiais desonestos, tanto entre policiais militares quanto entre civis. Porém, na avaliação da Brigada Militar, observa-se que as avaliações negativas se concentram entre os mais jovens, enquanto os mais velhos, especialmente aqueles acima de 59 anos, tendem a avaliar positivamente a instituição também nesse quesito (Teste realizado: Regressão Logística. Sig $=0,000)$. 


\section{k. Resultados contra o crime}

Pouco mais de $40 \%$ dos entrevistados consideram que o trabalho da BM e da PC tem contribuído para a redução dos crimes.

\section{Indicador de Confiança nas Polícias - ICPol}

Ao calcular a média dos percentuais positivos para ambas as polícias nestes 11 quesitos, chegamos ao Indicador de Confiança nas Polícias (ICPol) para a Brigada Militar e para a Polícia Civil. Os resultados estão sintetizados na figura 1:

Figura 1. ICPols da Brigada Militar e Polícia Civil.

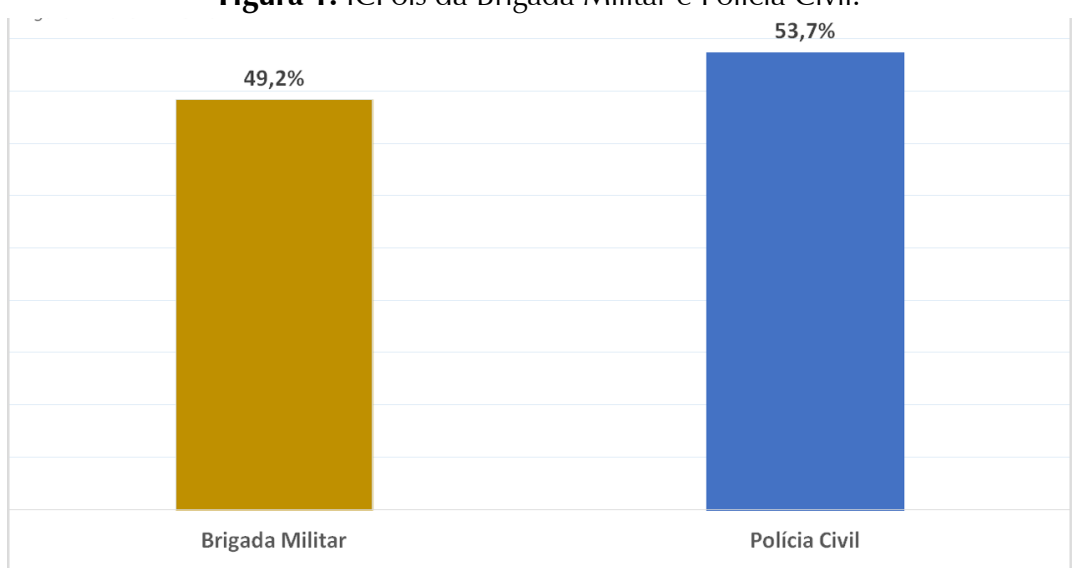

Fonte: I Pesquisa de Vitimização de Porto Alegre.

A maior confiança alcançada pela Polícia Civil, em comparação com o indicador da Brigada Militar, é consequência do melhor desempenho nos itens: "equidade no tratamento", "perguntas respondidas de forma satisfatória", "preparação dos policiais", e "não uso de violência". A BM, por seu turno, alcança avaliações mais positivas na comparação com a PC nos itens "percepção sobre resolução de problemas dos residentes" e "interação com os residentes". O que sugere um resultado relacionado à natureza da atuação da Brigada, o policiamento ostensivo que busca desencorajar determinadas práticas criminais e promover sensação de segurança. 


\section{O ICPol e o perfil dos entrevistados}

Foram observadas diferenças consideráveis quanto à confiança dos residentes nas polícias Militar e Civil, especialmente no que se refere à idade, cor/raça autodeclarada e renda dos entrevistados. Entre os mais jovens $s_{\perp}$ a Brigada Militar apresenta índices expressivamente mais baixos, se comparados aos alcançados entre os entrevistados mais velhos especialmente entre aqueles com 60 anos ou mais. Como se pode ver na figura 2, quanto menor a idade do entrevistado, menor a confiança na Brigada Militar. A Polícia Civil não apresenta discrepâncias significativas entre pessoas situadas nas faixas etárias de até 59 anos. Mas é também entre aqueles com 60 anos ou mais que alcança sua melhor avaliação.

Figura 2. ICPol BM e PC - por faixas de idade.

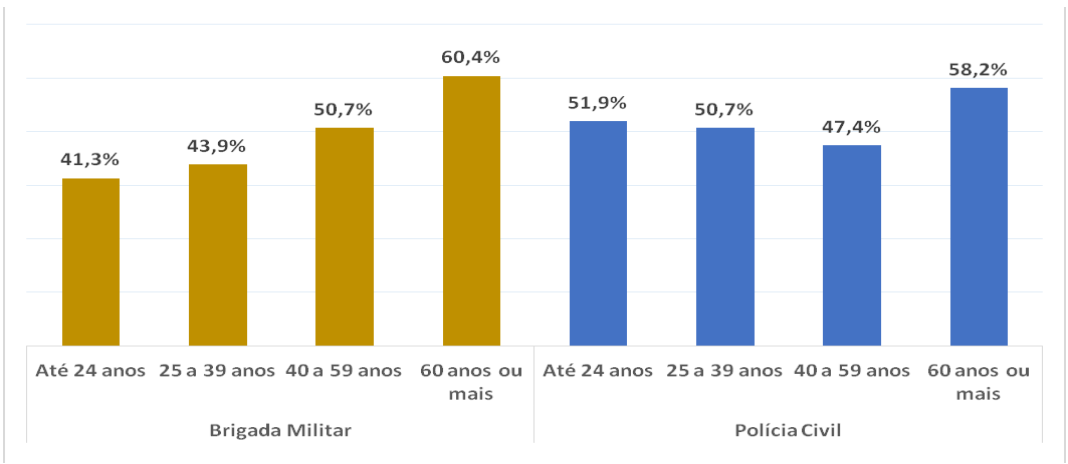

Fonte: I Pesquisa de Vitimização de Porto Alegre.

No que tange aos critérios de raça/cor dos entrevistados, a Brigada Militar logrou um índice de confiança mais baixo entre os negros, em comparação com o índice alcançado entre pessoas autodeclaradas brancas. Já o índice de confiança para a Polícia Civil aponta para uma avaliação mais positiva entre pessoas autodeclaradas negras, em comparação àquelas autodeclaradas brancas, conforme disposto na figura 3 . 
Figura 3. ICPol BM e PC - por cor/raça autodeclarada.

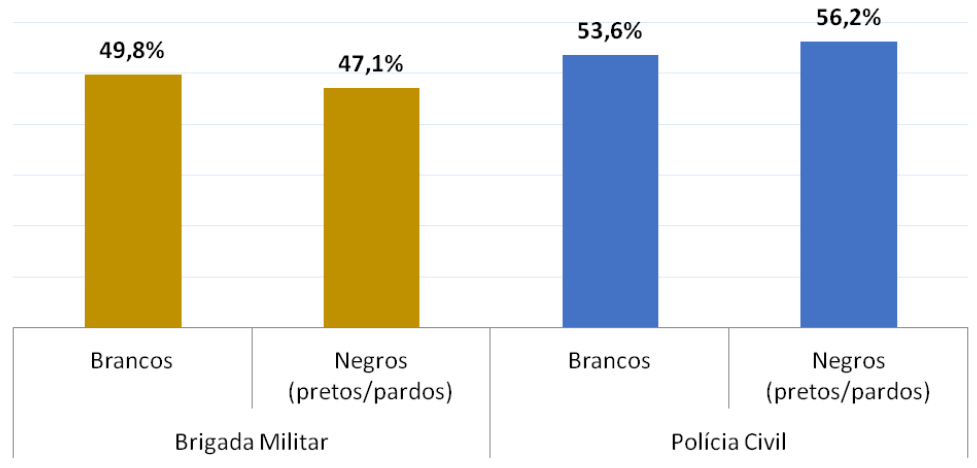

Fonte: I Pesquisa de Vitimização de Porto Alegre.

No que se refere ao perfil econômico dos entrevistados, é entre os mais pobres (renda familiar mensal de até dois salários mínimos) que a Brigada Militar tem sua pior avaliação. Já entre a parcela da população com renda mais elevada (renda familiar mensal de mais de seis salários), a BM encontra seu melhor escore. A Polícia Civil, por sua vez, também apresenta melhora do ICPol conforme cresce a renda familiar dos entrevistados; as diferenças entre os perfis de renda, porém, são menos expressivas se comparadas ao impacto desta variável na avaliação da Brigada Militar, como se vê na figura 4.

Figura 4. ICPol BM e PC - por renda familiar mensal.

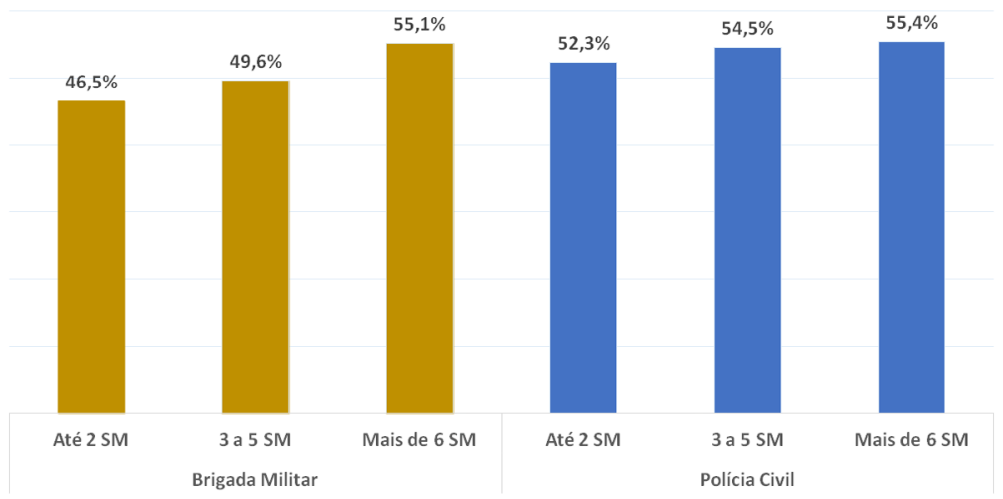

Fonte: I Pesquisa de Vitimização de Porto Alegre. 


\section{O perfil dos abordados pela BM}

Um total de $27,4 \%$ dos homens e $9,7 \%$ das mulheres da amostra foi abordado pela Brigada Militar nos últimos 12 meses. A probabilidade de ter sido abordado pela BM no período é maior entre os jovens de até 24 anos de idade ou adultos com idade entre 25 e 39 anos, conforme se vê na figura 5:

Figura 5. Abordados na rua pela BM - por faixa etária.

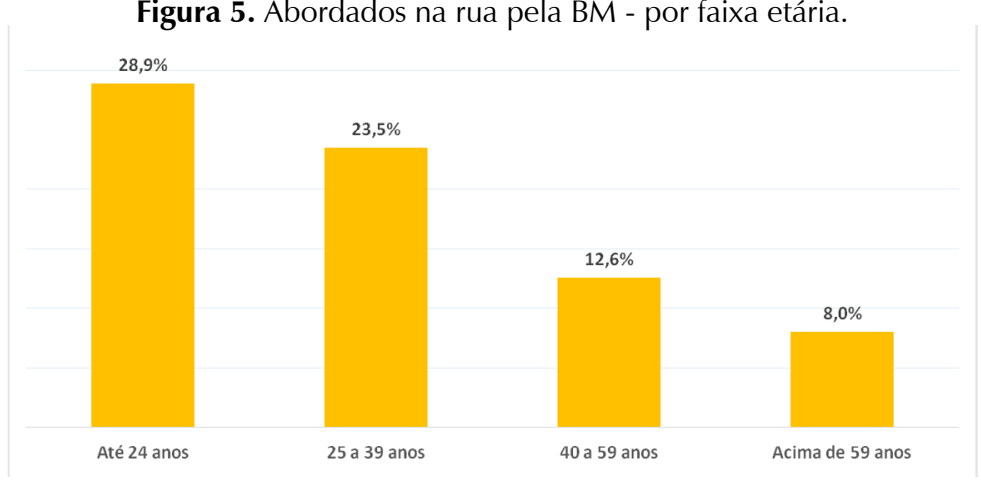

Fonte: I Pesquisa de Vitimização de Porto Alegre.

Pessoas negras (pretas e pardas) são abordadas em maior proporção, em comparação com pessoas brancas (Fig. 6).

Figura 6. Abordados na rua pela BM - por cor/raça autodeclarada.

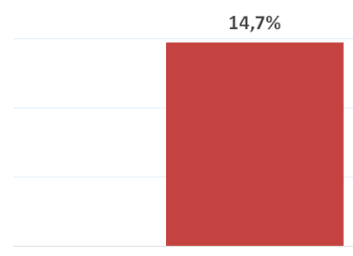

Brancos
$25,7 \%$

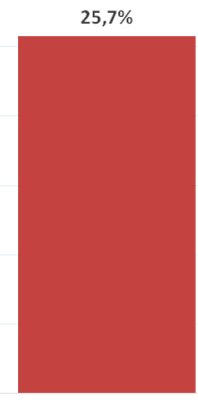

Negros (pretos/pardos)

Fonte: I Pesquisa de Vitimização de Porto Alegre. 
Pessoas com renda familiar mensal mais baixa têm maior probabilidade de serem abordadas pela Brigada Militar em comparação com pessoas com renda mais elevada (Fig. 7).

Figura 7. Abordados na rua pela BM - por renda familiar mensal.

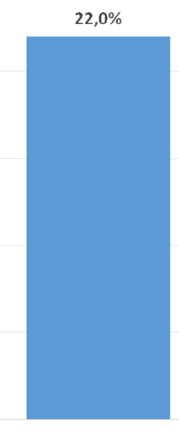

Até 2 Salários Minimos

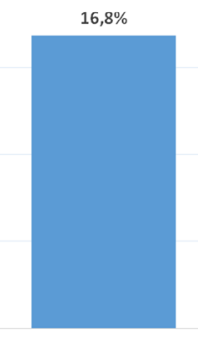

De 3 a 5 Salários Minimos
$14,5 \%$

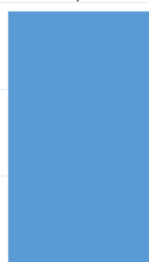

Acima de 6 Salários Mínimos

Fonte: I Pesquisa de Vitimização de Porto Alegre.

Já entre aqueles que procuraram a BM nos últimos 12 meses, há uma frequência maior de pessoas com escolaridade mais elevada (figura 8). Não se observou diferença estatisticamente significativa em relação à idade, cor/raça ou renda dos entrevistados que procuraram a corporação no período.

Figura 8. Procurou a BM, ligou para o 190 ou pediu ajuda - por escolaridade.

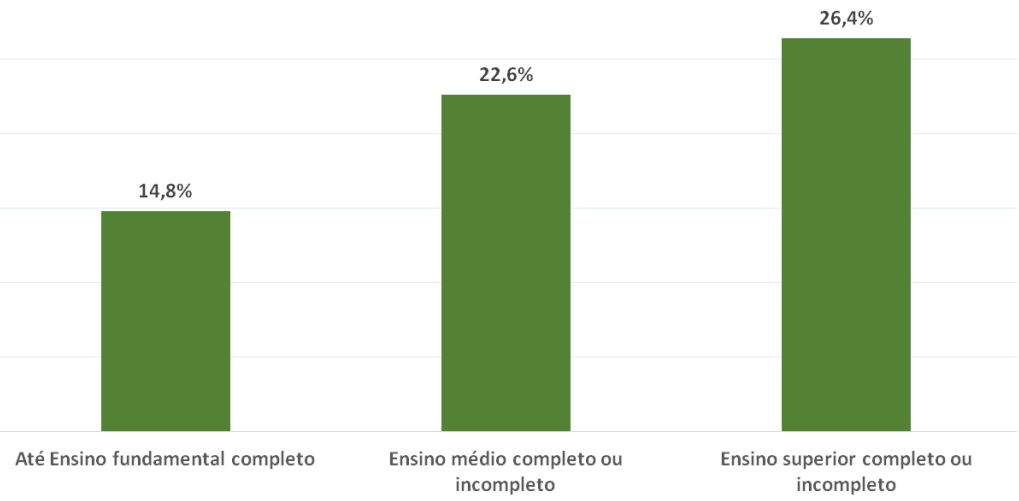

Fonte: I Pesquisa de Vitimização de Porto Alegre. 
O fato de que não se observa diferença estatisticamente significativa entre faixas etárias, níveis de renda e cor/raça autodeclarada entre aqueles que procuraram a Brigada Militar nos últimos 12 meses, aponta para uma discrepância no perfil daqueles que buscam voluntariamente a BM e aqueles que são selecionados para abordagem: os selecionados pela Brigada Militar na rua costumam ser jovens, negros ou pardos, e com renda familiar mensal inferior a dois salários mínimos.

\section{ICPol da BM: abordados x quem procurou a Brigada Militar}

Aqueles que foram apenas abordados pela Brigada Militar confiam menos nela $(\mathrm{ICPol}=42,2 \%)$. Os entrevistados que foram abordados e procuraram a BM no referido período são os que se mostram mais confiantes na corporação. Seria preciso saber se essas pessoas tiveram experiências distintas de abordagem, quando comparada aos demais que só foram abordados; se o contexto da abordagem que experimentaram foi diverso etc. Chama a atenção, de qualquer maneira, que, neste grupo (pessoas abordadas pela BM e que procuraram a BM), as opiniões mais favoráveis se concentrem entre homens brancos com renda mais alta e maior escolaridade. É possível que eles tenham sido abordados de forma mais respeitosa e que suas demandas tenham obtido maior atenção por parte da corporação (Fig. 9).

Figura 9. ICPol Brigada Militar.

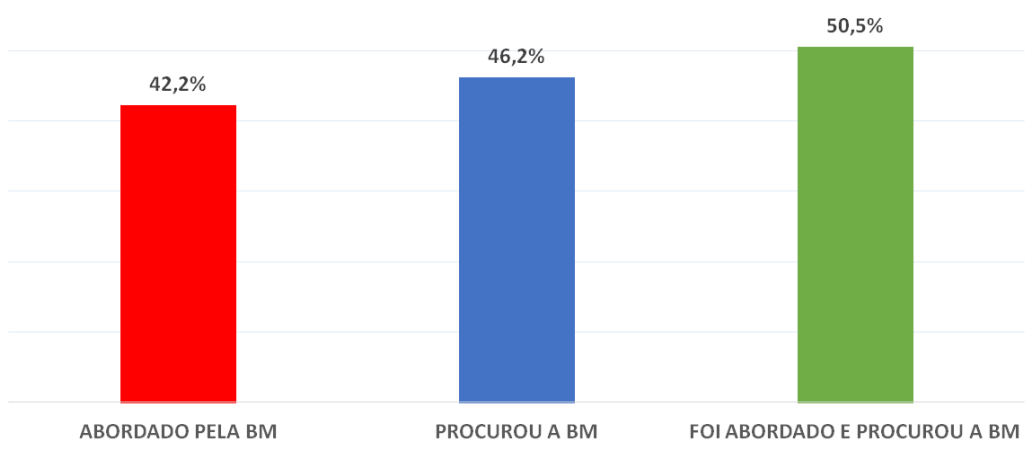

Fonte: I Pesquisa de Vitimização de Porto Alegre. 
Os entrevistados que foram abordados pela BM avaliam de forma negativa especialmente os itens referentes à violência policial (apenas 43,9\% concordam que a BM não é violenta) e à honestidade policial (apenas 47,7\% acreditam que os PMs são honestos). Nas figuras 10 e 11, observa-se como se comportam ambas as variáveis em função do perfil do entrevistado - se foi abordado pela BM, se procurou a BM ou se foi abordado e procurou a BM nos últimos 12 meses.

Figura 10. Policiais Militares não são violentos.

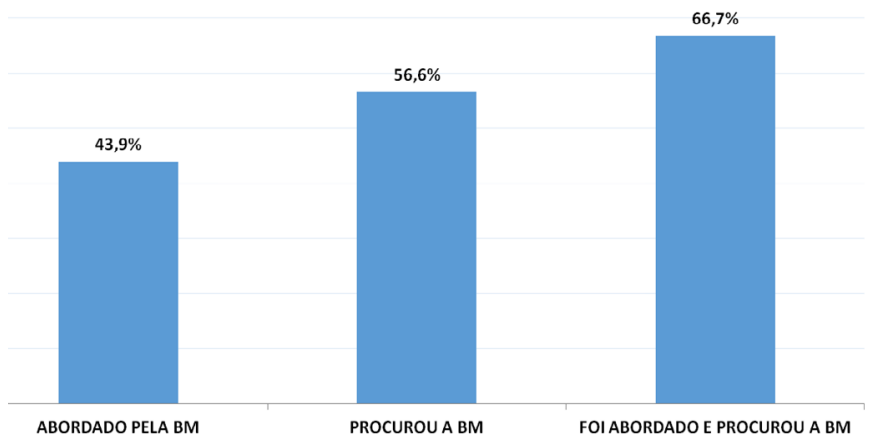

Fonte: I Pesquisa de Vitimização de Porto Alegre.

Figura 11. Policiais Militares são honestos.

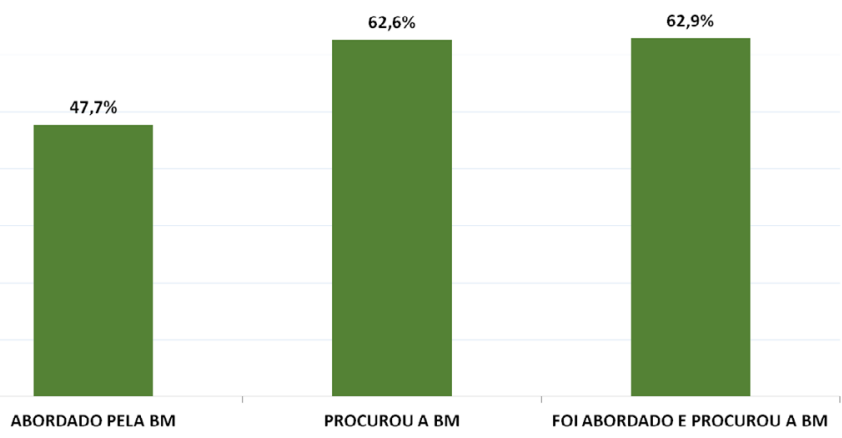

Fonte: I Pesquisa de Vitimização de Porto Alegre. 
Os dados aqui relatados evidenciam problemas importantes a serem considerados pelos gestores em Segurança Pública no RS, incluindo os dirigentes das polícias. Devem servir, também, como uma referência para o debate a respeito do modelo de polícia vigente no Brasil. Nenhuma instituição pode satisfazer-se com uma taxa de confiança próxima de 50\%, ainda mais quando os critérios empregados para a medição envolvem dimensões básicas da atenção à cidadania (como a satisfação com o atendimento recebido e imparcialidade) e juízos sobre características elementares (como preparação profissional, honestidade e comportamento não violento). Um hospital ou um veículo de imprensa que tivessem essa taxa de confiança seriam considerados de baixíssima qualidade. O problema mais grave, entretanto, sequer é este. O que a pesquisa demonstra é que a confiança nas polícias está fortemente correlacionada à renda, à idade e à cor das pessoas, sendo que tal correlação é bastante mais sensível no caso da Brigada Militar. O tema diz respeito a uma história de organização das polícias como estruturas de defesa do Estado, não da população e as distorções aqui apontadas são costumeiras no Brasil como o apontaram levantamentos empíricos como o do PNAD (1988) e vários estudos (Cardia, 1997). Essa circunstância é particularmente danosa para as polícias. Primeiro, porque a baixa confiança entre os jovens tende a se prolongar como consciência crítica para as próximas décadas, o que - se nada for feito - tende a debilitar a confiança nas polícias ainda mais. Segundo, porque uma polícia que é pouco confiável para pobres e negros é, comumente, uma instituição que não superou a demofobia (Aguiar, 2011) e o racismo.

\section{Como aumentar a confiança nas polícias}

O aumentar da confiança pública na polícia envolve, inicialmente, o desafio de superar algumas características antissociais presentes na subcultura policial, a começar pelo estilo de policiamento "nós e eles", pelo qual os policiais se percebem como membros de uma força estranha às comunidades, vocacionados à intervenção meramente repressiva, com comportamentos que 
reproduzem um estilo autoritário como que em relação de comando diante da cidadania ("eles") e que, no limite, autorizam a reprodução de práticas violentas e ilegais.

O problema, é claro, não diz respeito apenas aos policiais, como indivíduos, mas sobretudo às polícias, desde seus critérios de seleção e de formação, até as regras vigentes para promoções e a forma como os superiores tratam os subordinados. Importa lembrar que a Justiça Procedimental deve valer não apenas "externamente", nas relações entre os policiais e o público, mas também internamente, nas interações entre os policiais e entre eles e seus superiores. Como exigir de um policial que ele escute com atenção o que as pessoas desejam lhe contar, se ele próprio não tem o direito de expressar sua opinião para seus superiores? Tyler, Callahan e Frost (2007, apud Kunard; Moe, 2015) encontraram que os policiais que se sentem respeitados por seus superiores e por seus pares aceitam com mais facilidade as definições estratégicas e cumprem as decisões voluntariamente.

Na relação dos policiais com o público devemos lembrar os princípios de Robert Peel ${ }^{11}$, que fundaram a concepção moderna de policiamento. Segundo o 7o princípio, é preciso compreender que "o povo é a polícia e que a polícia é o povo", que os policiais são cidadãos que são parte do público, dele se diferenciando apenas pelo fato de serem profissionais dedicados integralmente à segurança pública. Uma das decorrências dessa visão é a de que os policiais devem confiar no público, ao invés de enquadrálo naturalmente no pressuposto da suspeição, ou imaginar que podem alcançar indicadores de qualidade em seu trabalho sem a colaboração ativa da cidadania. O desafio foi sintetizado por Westmarland (2010, p. 291).

A confiança do público na polícia é um processo de duas mãos. Para que as pessoas possam confiar na polícia elas precisam sentir que ${ }^{11} \mathrm{O} 70$ princípio do policiamento da lista de nove princípios elaborados por Robert Peel no final do século XIX assinala: "A Polícia, em todos os tempos, deve manter um relacionamento com o público que reforce a tradição histórica de que a polícia é o público e o público é a polícia, a polícia é formada por membros da população que são pagos para dar atenção em 
são ouvidas e que suas preocupações contam. Para realizar esse trabalho, entretanto, a polícia deve estar preparada para confiar no público.

O contato com o público realizado pelos policiais é um tema central, quando discutimos confiança, com expressiva repercussão na eficiência do trabalho das instituições. Qualificar o contato dos policiais com o público, assim como levar em conta a capacidade de comunicação, de cordialidade e de resposta a situações de tensão daqueles que pretendem ser policiais, são desafios que podem ser resolvidos pelas polícias mesmo quando os recursos são insuficientes ou quando há outros problemas estruturais a serem superados.

Sabe-se que as estratégias de policiamento comunitário, marcadas pelo contato direto dos policiais com o público, podem ser efetivas na construção de relações de confiança (Pinheiro, 1997; Muniz, 1997; Souza, 2001). A mera presença dos policiais na rua, e a visibilidade decorrente, não são suficientes, todavia, para promover confiança (Tuffin et al., 2006, apud Myhill; Bradford, 2012). O engajamento dos residentes e a capacidade dos policiais de resolver problemas são, segundo Hohl et al. (2010), o que fará a diferença. Vários são os estudos que corroboram o caráter decisivo do engajamento das comunidades com o trabalho da polícia ${ }^{\mathbf{1 2}}$. Para que o engajamento seja possível, é preciso ouvir a comunidade e identificar quais são os temas que realmente preocupam os residentes com relação à segurança. Isso implica assumir o compromisso de que as prioridades do policiamento em cada região devem ser definidas pelos residentes e não pela polícia.

Há estudos que demonstram que as regiões onde as pessoas consideram que os policiais são respeitosos são aquelas que experimentam as maiores taxas de redução do crime e da violência. Sherman et al. (1997) lembram as avaliações sobre a chamada "experiência de Milwaukee" (Milwaukee Domestic Violence Experiment) a qual revelou que os agressores que avaliaram terem sido tratados de forma respeitosa pelos policiais foram os que menos reincidiram. Assim, é possível que o fenômeno da reincidência seja também impactado

tempo integral aos deveres que incumbem a cada cidadão, no interesse do bem-estar da comunidade e da sua existência".

${ }^{12}$ Ver, por exemplo, o relato da experiência de Hammersmith, em Londres (Rehman, 2009). 
pela forma como os policiais agem e pelo tempo que oferecem para ouvir a versão dos agressores. Estudo de Tyler e Fagan (2008), em Nova lorque, mostrou que os motoristas que cometeram infrações de trânsito e que foram tratados de forma justa por policiais ao serem multados, formaram opinião mais favorável à polícia do que a que possuíam antes da ocorrência, o que reforça a conclusão de que o processo no qual se realiza a interação entre os policiais e o público tende a ser mais importante do que o resultado em si mesmo.

Ao mesmo tempo, é preciso ter em mente a relação assimétrica identificada por Skogan (2006), para quem a relação face a face com o público também oferece oportunidades para a produção de danos à imagem da polícia e à confiança na instituição, só que maiores. Uma intervenção desastrada da polícia, um ato de violência ou discriminação ou caso de corrupção, na medida em que se tornem conhecidos, tendem a reduzir imediatamente a confiança na polícia, colocando a perder os esforços de vários anos. Também aqui, é mais simples e rápido destruir do que construir.

A obrigação de tratar bem as pessoas e, particularmente, as vítimas de crimes, não pode ser assegurada apenas com base em orientações gerais ou a partir da formação dos policiais. É preciso que as polícias possuam regras a respeito, que promovam o monitoramento efetivo dos atendimentos prestados. Como ocorre em muitos países, as ouvidorias das polícias deveriam ouvir amostras aleatórias entre as vítimas sobre como foram tratadas pelos policiais. O cotidiano da gestão de polícia, no mais, deve contar com mecanismo regular de monitoramento dos atendimentos, a partir de contato telefônico com amostra representativa dos cidadãos que procuraram a polícia por algum motivo.

Esse processo deve ser integrado, com destaque a um sistema objetivo de avaliação do mérito dos policiais, repercutindo nas carreiras. Se os policiais souberem que as pessoas que eles atenderam poderão informar seus superiores sobre a atenção que receberam e que isso será considerado na avaliação de seu mérito, então a qualidade do atendimento irá melhorar rapidamente. Na relação com as vítimas, é muito importante que as polícias as mantenham informadas sobre o andamento das investigações, o que, 
no caso brasileiro, deveria ser uma diretriz da Polícia Civil. Esse cuidado tende a aumentar em muito a confiança das pessoas.

Isso permite perceber a importância de uma estratégia efetiva de comunicação social. Como regra, nossas polícias não se dirigem ao público. Nas poucas vezes em que lideranças policiais se manifestam publicamente, isso se dá quando da repercussão de algum crime mais grave e que despertou o interesse da mídia. As polícias, entretanto, não podem se relacionar com a opinião pública reativamente. É preciso que elas tenham canais próprios de comunicação, que possam informar sobre seus objetivos, que contribuam para reduzir o medo disseminado e que instruam as comunidades a respeito de riscos reais e sobre formas de prevenção do crime e da violência. Tendo presente que as piores avaliações das polícias estão concentradas entre os mais jovens, essa estratégia deverá oferecer forte atenção às redes sociais. Quanto às comunidades, o trabalho deverá ser pensado a partir da inclusão e do engajamento dos residentes e da cooperação das entidades da sociedade civil, desde as associações de moradores, igrejas, escolas de samba e clubes de futebol, até os empresários locais, escolas, pessoal da área da saúde pública, entre outras.

Marcos Flávio Rolim é Doutor em Sociologia pela UFRGS, coordenador de Comunicação Social do TCE-RS, integrante do Conselho Administrativo do CIPDH (vinculado à UNESCO) e membro fundador do Fórum Brasileiro de Segurança Pública.

$\equiv$ marcos@rolim.com.br

Daiana Hermann é Mestra em Antropologia Social pela UFRGS e doutoranda no Programa de Pós-Graduação em Sociologia/UFRGS.

Ðdaianahermann86@gmail.com

\section{Referências}

1. AGUIAR, Thais Florêncio de. A demofobia na democracia moderna. Dados: Revista de Ciências Sociais, Rio de Janeiro, v. 54, n.4, p. 609-50, 2011.

2. BEATO, Cláudio. Policiamento Comunitário: a visão dos policiais. Universidade Federal de Minas Gerais. Centro de Estudos de Criminalidade e Segurança Pública, 
2009. Disponível em: http://www.crisp.ufmg.br/wp-content/uploads/2016/10/ T050_Relat\%C3\%B3rio_PoliciamentoComunit\%C3\%A1rio_2009.pdf

3. BRADFORD, Ben. The Quality of Police Contact: Procedural Justice Concerns among Victims of Crime in London. LSE Working Paper, 2009.

4. BRADFORD, Ben; STANKO, Elizabeth A.; JACKSON, Jonathan. Public Encounters with the Police: Using Public Opinion Surveys to Help Understand and Improve Contact and Confidence. Policing: a Journal of Policy and Practice, v. 3, n. 2, p. 139-48, 2009.

5. CARDIA, Nancy. O medo da polícia e as graves violações dos direitos humanos. São Paulo, Tempo Social, v. 9, n. 1, p. 249-65, 1997.

6. HAGAN, John; ALBONETTI, Celesta. Race, class, and the perception of criminal injustice in America. American Journal of Sociology, n. 88, p. 329-55, 1982.

7. HAWDON, James. Legitimacy, trust, social capital, and policing styles: a theoretical statement. Police Quarterly, n. 11, p. 182-201, 2008.

8. IPEA - Instituto de Pesquisa Econômica Aplicada. O Sistema de Indicadores de Percepção Social (SIPS) - Segurança Pública, 2011. Disponível em: http://www. ipea.gov.br

9. HOHL, Katrin; BRADFORD, Ben; STANKO, Elizabeth A. Influencing Trust and Confidence in the London Metropolitan Police. Brit. J. Criminol., n. 50, p. 491513, 2010.

10. JANG, Hyunseok; JOO, Hee-Jong; ZHAO, Jihong (Solomon). Determinants of Public Confidence in Police: an International Perspective. Journal of Criminal Justice, n. 38, p. 57-68, 2010.

11. KANE, Robert J. Compromised police legitimacy as a predictor of violence crime in structurally disadvantaged communities. Criminology, n. 43, p. 469-98, 2005.

12. KUNARD, Laura; MOE, Charlene. Procedural Justice for Law Enforcement: An Overview. Washington: Office of Community Oriented Policing Services, 2015.

13. MASTROFSKI, Stephen D.; SNIPES, Jeffrey B.; SUPINA, Anne E. Compliance on demand: the public's response to specific police requests. Journal of Research in Crime and Delinquency, n. 33, p. 269-305, 1996.

14. MUNIZ, Jaqueline et al. Resistências e dificuldades de um programa de policiamento comunitário. São Paulo: Tempo Social, v. 9, n. 1, p. 197-213, 1997. 15. MYHILL, Andy; BRADFORD, Ben. Can Police Enhance Public Confidence by Improving Quality of Service? Results from Two Surveys in England and Wales, Policing and Society: An international Journal of Research and Policy. v. 22, n. 4, 2012.

16. PINHEIRO, Paulo Sérgio. Violência, crime e sistemas policiais em países de novas democracias. Tempo Social, 9 (1), p. 43-52, 1997.

17. PNAD. Participação político social. v. 1. Justiça e Vitimização. Rio de Janeiro: IBGE, 1988.

18. REHMAN, Ubaid-ul. The Hammersmith Initiative: An Example of How to Impact and Improve Public Confidence in Policing, Policing, v. 3, n. 4, p. 310-17, 2009. 
19. ROSENBAUM, Dennis P.; LAWRENCE, Daniel S.; HARTNETT, Susan M.; McDEVITT, Jack; POSICK, Chad. Measuring Procedural Justice and Legitimacy at the Local Level: the Police-Community Interaction Survey. Journal of Experimental Criminology, v. 11, n. 3, p. 335-66, 2015. Disponível em: https:// chicagopatf.org/wp-content/uploads/2016/03/Measuring-procedural-justice-andlegitimacy-at-the-local-level-2015.pdf

20. SANTOS, Andreia dos. Legitimidade policial: uma análise do trabalho policial na Região Metropolitana de Belo Horizonte. In: XII Congresso da Sociedade Brasileira de Sociologia, 2002, Belo Horizonte. Anais. Disponível em: http:// www.sbsociologia.com.br/portal/index.php?option $=$ com_docman\&task =doc download\&gid $=23 \&$ ltemid $=171$

21. SHERMAN, Lawrence. W. Defiance, Deterrence, and Irrelevance: a Theory of the Criminal Sanction. Journal of Research in Crime and Delinquency, 30, p. 445-73, 1993.

22. SHERMAN, Lawrence et al. Preventing Crime: What Works, What doesn't, What's Promising. A Report to the United States Congress, Prepared for the National Institute of Justice, 1997. Disponível em: https://www.ncjrs.gov/ pdffiles/171676.pdf

23. SHIRLEY, Robert. W. Atitudes com relação à polícia em uma favela no sul do Brasil. São Paulo: Tempo Social, v. 9, n. 1, p. 215-31, 1997.

24. SILVA, Geélison F.; BEATO, Cláudio. Confiança na polícia em Minas Gerais: o efeito da percepção de eficiência e do contato individual. Opinião Pública, Campinas, v. 19, n. 1, p. 118-53, 2013.

25. SKOGAN, Wesley G. Asymmetry in the Impact of Encounters With the Police. Policing and Society, v. 16, n. 2, p. 99-126, 2006.

26. STANKO, Elizabeth A.; BRADFORD, Ben. Beyond Measuring How Good a Job Police are Doing: The MPS Model of Confidence in Policing. Policing: A Journal of Policy and Practice, v. 3, n. 4, p. 322-30, 2009.

27. SOUZA, Elenice. Organização policial e os desafios da democracia. Teoria e Sociedade, Belo Horizonte, v. 7, p. 151-72, 2001.

28. TYLER, Tom R. Why People Obey the Law. New Haven: Yale University Press, 1990.

29. TYLER, Tom R.; FAGAN, Jeffrey. Legitimacy and Cooperation: Why Do People Help the Police Fight Crime in their Communities? Ohio State Journal of Criminal Law, n. 6, p. 231-75, 2008.

30. TYLER, Tom R.; HUO, Yuen. Trust in the Law: Encouraging Public Cooperation with the Police and Courts. New York: Russell Sage Foundation, 2002.

31. WESTMARLAND, Louise. Dodgy Customers? Can the Police Ever Trust the Public? Policing, v. 4, n. 3, p. 291-97, 2010.

32. ZANETIC, André; MANSO, Bruno Paes, NATAL, Ariadne Lima; OLIVEIRA, Thiago Rodrigues. Legitimidade da polícia: Segurança pública para além da dissuasão. Civitas, Porto Alegre, v. 16, n. 4, p. 148-73, 2016.

Recebido: 10.03.2018

Aceite: 26.06 .2018 